\title{
The Devil is in the Details: When Holistic Thinkers React Negatively to Incongruent Information
}

\author{
Sydney Chinchanachokchai \\ University of Wisconsin-Eau Claire \\ E-mail: chinchb@uwec.edu \\ Hayden Noel \\ University of Illinois at Urbana-Champaign \\ E-mail: hnoel@illinois.edu
}

\begin{abstract}
This research examines the effects of thinking styles (holistic vs. analytic) and different levels of information congruity on product evaluations. Two experimental studies show that presenting more details in a message matches the analytic thinking style, thus leading to higher evaluations of extremely incongruent information, from analytic thinkers and lower evaluations from holistic thinkers.
\end{abstract}

Keywords: Thinking Styles, Information Processing, Advertising, Congruent Message, Schema Congruity

\section{INTRODUCTION}

New products are usually accompanied by new information that describes its features or usage to facilitate purchase decisions. Functional products, such as smartphones, contain many functional attributes (Dhar \& Wertenbroch, 2000) and may need more detailed, attribute-based descriptions to help consumers fully understand their functions. Thus, the information may have to be presented in a way that is easy for consumers to see and compare the product with its competitors.

Information that is moderately incongruent to the schema is judged more favorably than extremely incongruent information (Meyers-Levy et al., 1994). Previous research shows how thinking styles affect perceived congruity as reflected in brand extensions but only looks at category-level information presentation (Monga \& John, 2007; 2010). This research examines how holistic and analytic consumers react to different levels of information congruity when the information is presented in an 
attribute-based format. Information presented in different formats may facilitate one type of processing style and inhibit others. Two studies demonstrate how presenting detailed information that is incongruent to the schema negatively impacts holistic consumers while helping analytic consumers.

\section{LITERATURE REVIEW}

\section{Holistic-Analytic Thinking Styles}

Thinking styles - holistic versus analytic processing - affect consumer information processing and how one deals with contradiction. Holistic thinkers tend to focus on the relationship between the focal object and the field, whereas analytic thinkers tend to focus on the attributes of the object to assign it to categories (Nisbett et al., 2001). A holistic thinking style is usually exhibited by people of East Asian cultures, while an analytic thinking style is found among people of Western cultures (Miyamoto et al., 2006). Although the difference between holistic and analytic thinking styles is prominent among people from different cultural backgrounds, studies have found that thinking styles can also be manipulated using priming methods (Monga \& John, 2007) or measured using the Analysis-Holism scale (Choi et al., 2007).

Holistic thinkers have a more holistic sense of causality because they draw on a wider range of factors to explain events, and they show more hindsight bias (Roese \& Vohs 2012), or the tendency to assume one knew all along that a given outcome was likely. This tendency to group objects based on relational-contextual variables based on hindsight bias may affect how holistic thinkers categorize new information to their existing schema differently from analytic thinkers.

\section{Thinking Styles and Schema Congruity}

Product evaluations are affected by the congruity of information to the existing schema. The schema-congruent information will lead to a mildly positive response because consumers find it easy to match with the existing schema without much effort. Information which is moderately incongruent to the schema will generate more extensive processing and arousal, leading to a more favorable response through the act of discovery. On the contrary, information which is extremely incongruent to the schema is unlikely to be resolved, thus causing frustration and helplessness and leading to a negative response (Meyers-Levy \& Tybout, 1989).

Holistic thinkers react more positively to information that is different from their existing schema (brand extension); this effect is particularly true for functional brands 
(Monga \& John, 2007; 2010). Analytic thinkers have more difficulty connecting brand extensions that fit weakly with the parent brands (Monga \& John, 2010). However, this difficulty may be alleviated by the presentation format of the information, which plays a role in how consumers process the information (Bettman \& Zins, 1979). Therefore, when information is presented in a format congruent with consumers' information processing, it leads to a more effective message for them (Meyers-Levy \& Tybout, 1989). Analytic consumers overcome the resistance to distant extensions of functional brands by reading additional information about the extension (Monga \& John, 2010). This is because the information format is compatible with the itemspecific, attribute-based style of thinking exhibited by analytic consumers. The additional information may make consumers process information on a piecemeal basis.

The literature on brand extension generally has focused on category-level information (e.g., products and brands) without looking at how the information is presented (Aaker \& Keller, 1990). Consumers are required to judge how congruent the extension is to the parent brands without attribute information, which might be more in line with holistic thinking. However, analytic thinkers may need other information to ease the process of making distant connections. Since analytic thinkers process information on an attribute-by-attribute basis (Nisbett et al., 2001), presenting information on an attribute basis (piecemeal) should fit more with the analytic style and facilitate the processing of information.

Despite the attribute-based information presentation, holistic thinkers may still be able to make a connection between the new information and the schema more effectively than analytic thinkers when the information is moderately incongruent with the existing schema due to their ability to see the relationship between the two. The moderately incongruent information may have some new information but still maintain similar characteristics to the existing schema, which may be considered easy to process for holistic thinkers. Therefore, holistic thinkers should demonstrate more positive responses to the moderately incongruent information than analytic thinkers.

H1: When information is moderately incongruent to their schema, holistic thinkers will have more positive responses than analytic thinkers.

When the information is extremely incongruent with the existing schema (extreme mismatch), presenting information on an attribute basis may lead analytic thinkers to focus on individual attributes but may cause holistic thinkers to experience increased difficulty, leading to lower evaluations. 
$\mathrm{H} 2$ : When information is extremely incongruent to their schema, analytic thinkers will have more positive responses than holistic thinkers.

\section{STUDY 1}

\section{Method}

\section{- Participants and Design}

Undergraduate students ( $\mathrm{N}=120 ; 66$ male; 54 female) participated in the study of a 2 (thinking styles; holistic/analytic thinking) x 3 (congruent/ moderately/extremely incongruent) between-subjects design.

\section{- Stimuli}

An ad for a Blackberry smartphone was created with the brand written at the top and attributes of the product and a picture listed below. We manipulated congruity by changing information about the attributes of the phone. Under the congruent condition, the description of attributes matched the ad title and picture. In the moderately incongruent condition, some characteristics from other products that did not belong to the target product were mixed into the description along with the target product attributes. The extremely incongruent condition displayed the ad title with attributes that did not match with the target product (Sujan, 1985).

\section{- Procedure}

Participants were primed with either instructions to process an image in a holistic manner or in an analytic manner. Holistic-primed participants were asked to focus attention on the background, whereas analytic-primed participants were instructed to look for specific objects in the picture (Monga \& John, 2007). After the priming task, they were shown the print ad. The participants formed an impression of the ad and gave their overall evaluation of the product and their purchase intention. Then they completed the Analysis-Holism Scale (AHS). Higher scores on the AHS scale indicated a more holistic mindset (Choi et al., 2007).

\section{Results}

\section{- Manipulation Check}

The congruent ad was rated as more congruent to the product than the moderately incongruent and extremely incongruent conditions (5.10, 4.52, and 
3.38 , respectively) $F(2,117)=19.95, p<.01$. The AHS scale score showed that the thinking styles were successfully manipulated. Holistic-primed participants scored higher than the analytic-primed participants (4.78 vs. $4.56, F(1,119)=8.93, p<.01)$.

\section{- Product Evaluation}

Holistic-primed and analytic-primed participants were not much different in the product evaluation when the target ads were congruent with the product knowledge $\left(\mathrm{M}_{\text {holistic }} 4.52\right.$ vs. $\mathrm{M}_{\text {analytic }} 4.89$, respectively, $p=$ n.s.). In the moderately incongruent condition, holistic-primed participants evaluated the product slightly higher than those who had been analytic-primed $\left(\mathrm{M}_{\text {holistic }} 4.90\right.$ vs. $\mathrm{M}_{\text {analytic }} 4.60, p=$ n.s.). However, in the extremely incongruent condition, holistic-primed participants evaluated the target product much lower than the analytic-primed participants did $\left(\mathrm{M}_{\text {holistic }} 3.40\right.$ vs. $\left.\mathrm{M}_{\text {analytic }} 4.45, p<.05\right)$. There was a significant two-way interaction between the level of congruity and thinking styles, $F(2,114)=2.99, p<.05$.

\section{- Purchase Intention}

There was a significant interaction effect between the level of congruity and thinking styles $F(2,114)=4.62, p<.05$. Holistic and analytic thinkers were not different under the congruent condition ( $\mathrm{M}_{\text {holistic }} 3.95$ vs. $\mathrm{M}_{\text {analytic }} 4.21, p=\mathrm{n} . \mathrm{s}$.), but holistic thinkers showed higher purchase intention than analytic thinkers did when the target ad was moderately incongruent with their product knowledge $\left(\mathrm{M}_{\text {holistic }}\right.$ 4.40 vs. $\left.\mathrm{M}_{\text {analytic }} 3.50, p<.05\right)$. However, analytic thinkers showed higher purchase intention than holistic thinkers when the ad was extremely incongruent $\left(\mathrm{M}_{\text {analytic }}\right.$ 4.20 vs. $\mathrm{M}_{\text {holistic }} 2.95, p<.05$ ).

\section{STUDY 2}

\section{Method}

\section{- Participants and Design}

Undergraduate students $(\mathrm{N}=122 ; 57$ male; 65 female $)$ participated in the study of a 2 (thinking styles; holistic/analytic) x 3 (congruent/ moderately/extremely incongruent) between-subjects design.

\section{- Priming Manipulation}

Thinking style was manipulated by telling participants that the study was interested in measuring the English writing skills of elementary school students in the first and fourth grades. They were asked to read and evaluate the quality of two 
essays from different grade levels. In addition to reading, they were required to circle the pronouns in the essays. In the analytic prime condition, participants circled the pronouns representing the independent self (e.g., I, me), whereas those in the holistic prime condition circled pronouns that represent the interdependent self (e.g., we, us) (Kuhnen et al., 2001).

\section{- Stimuli}

We changed the product in the ad to an Amazon Kindle to test generalizability and to present an up-to-date product category that would be of interest to the target group.

\section{- Procedure}

Participants read the essays and circled pronouns according to a condition. Then they looked and formed an impression of the Kindle Fire print ad. Similar to the procedure in Study 1, they evaluated the product and their purchase intention, then completed the AHS scale.

\section{Results}

\section{- Manipulation Check}

The congruent information condition was rated as more consistent than the moderately and extremely incongruent condition (4.50 vs. 4.82 vs. 5.12, respectively, $F(2,119)=3.012, p<.05)$. The AHS scale score shows that the thinking style (I/We) essay manipulation was successful. Holistic-primed participants scored higher than analytic-primed participants (4.81 vs. $4.48, F(1,120)$ $=7.73, p<.01)$.

\section{- Product Evaluation}

There is a significant two-way interaction between thinking style and level of information congruity $[F(2,116)=3.39, p<.05]$. Holistic-primed thinkers were not much different from the analytic-primed thinkers when the attribute information was congruent with the product category $\left(\mathrm{M}_{\text {holistic }} 5.25\right.$ vs. $\mathrm{M}_{\text {analytic }} 5.18, p=\mathrm{n}$.s.). When the attribute information was moderately incongruent with the existing information, holistic-primed thinkers evaluated the product slightly higher than the analytic-primed thinkers did ( $\mathrm{M}_{\text {holistic }} 5.53$ vs. $\mathrm{M}_{\text {analytic }} 4.90, p=$ n.s. $)$. However, analytic-primed thinkers rated the product significantly higher when the attribute information was extremely incongruent $\left(\mathrm{M}_{\text {analytic }} 5.52\right.$ vs. $\left.\mathrm{M}_{\text {holistic }} 4.86, p<.05\right)$. 


\section{- Purchase Intention}

The results were similar to product evaluation. Both groups were equally likely to purchase the product in the congruent condition $\left(\mathrm{M}_{\text {holistic }} 3.35\right.$ vs. $\mathrm{M}_{\text {analytic }}$ 3.54, $p=$ n.s.). In the moderately incongruent condition, holistic-primed thinkers were more likely to purchase the product than the analytic-primed thinkers $\left(\mathrm{M}_{\text {holistic }}\right.$ 4.05 vs. $\left.\mathrm{M}_{\text {analytic }} 3.15, p<.05\right)$. In the extreme incongruence condition, the results were opposite. Analytic-primed thinkers were more likely to say that they would purchase the product than the holistic-primed thinkers were $\left(\mathrm{M}_{\text {analytic }} 4.11\right.$ vs. $\left.\mathrm{M}_{\text {holistic }} 3.50, p<.1\right), F(2,116)=3.09, p<.05$.

\section{GENERAL DISCUSSION}

Our research broadens the understanding of how thinking styles interact with schema congruity when the information is presented in an attribute-based format. The results demonstrate that presentation format does matter, especially with different thinking styles. Under the moderately incongruent condition, holistic thinkers have slightly higher product evaluations but indicate significantly higher purchase intention than that of analytic thinkers. The non-significant difference may be attributed to different presentation formats. While holistic thinkers are still able to make a connection between new information and their existing product knowledge, the presentation format (attribute-based) conflicts with their processing style and makes the evaluation not as high as it should be. On the contrary, when information is extremely incongruent to existing product features, holistic thinkers evaluate the product significantly lower and are less likely to purchase the product than analytic thinkers. This occurs since the presentation format of the information is constructed to better match the processing style of analytic thinkers. In this research, we did not examine the underlying processes that could result in more positive evaluations among analytic thinkers than that of holistic thinkers when presented with very incongruent information. Future research could use process measures to examine this issue in greater detail.

\section{REFERENCES}

Aaker, D.A., \& Keller, K.L. (1990). Consumer evaluations of brand extensions. Journal of Marketing, 54(1), 27-41. http://dx.doi.org/10.2307/1252171

Bettman, J.R., \& Zins, M.A. (1979). Information format and choice task effects in decision making. Journal of Consumer Research, 6(2), 141-153. http://dx.doi.org/10.1086/208757 
Choi, I., Koo, M.K., \& Choi, J.A. (2007). Individual differences in analytic versus holistic Thinking. Personality and Social Psychology Bulletin, 33(5), 691-375. http://dx.doi.org/10.1177/0146167206298568

Dhar, R., \& Wertenbroch, K. (2000). Consumer choice between hedonic and utilitarian goods. Journal of Marketing Research, 37(1), 60-71. http://dx.doi.org/10.1509/jmkr.37.1.60.18718

Kuhnen, U., Hannover, B., \& Schubert, B. (2001). The semantic-procedural interface model of the self: the role of self-knowledge for context-dependent versus context-independent modes of thinking. Journal of Personality and Social Psychology, 80(3), 397-409. http://dx.doi.org/10.1037//0022-3514.80.3.397

Meyers-Levy, J., Louie, T.A., \& Curren, M.T. (1994). How does the congruity of brand names affect evaluations of brand name extensions? Journal of Applied Psychology, 79(1), 46-53. http://dx.doi.org/10.1037/0021-9010.79.1.46

Meyers-Levy, J., \& Tybout, A.M. (1989). Schema congruity as a basis for product evaluation. Journal of Consumer Research, 16(2), 39-54.

Miyamoto, Y., Nisbett, R.E., \& Masuda, T. (2006). Culture and the physical environment holistic versus analytic perceptual affordances. Psychological Science, 17(2), 113-119. http://dx.doi.org/10.1111/j.1467-9280.2006.01673.x

Monga, A.B., \& John, D.R. (2007). Cultural differences in brand extension evaluation: the influence of analytic versus holistic thinking. Journal of Consumer Research, 33(4), 529 - 536. http://dx.doi.org/10.1086/510227

Monga, A.B., \& John, D.R. (2010). What makes brands elastic? The influence of brand concept and styles of thinking on brand extension evaluation. Journal of Marketing, 74(3), 80-92. http://dx.doi.org/10.1509/jmkg.74.3.80

Nisbett, R.E., Peng, K., Choi, I., \& Norenzayan, A. (2001). Culture and systems of thought: holistic versus analytic cognition. Psychology Review, 108(2), 291-310. http://dx.doi.org/10.1037//0033-295X.108.2.291 
Roese, N.J., \& Vohs, K.D. (2012). Hindsight bias. Perspectives on Psychological Science, 7(5), 411-426. http://dx.doi.org/10.1177/1745691612454303

Sujan, M. (1985). Consumer knowledge: Effects on evaluation strategies mediating consumer judgments. Journal of Consumer Research, 12(1), 31-46. http://dx.doi.org/10.1086/209033 
